\title{
Study on desalination of brackish water and causes of arid area
}

\author{
Ning cao \\ Xijing University, china \\ 254560472@qq.com
}

Keywords: brackish water; causes; hazards; distribution; desalination technology; research

\begin{abstract}
References to relevant literature it summarizes the definition of standards, distribution and harm of brackish water, analysis of the causes of brackish water, and reviews the current use of more distillation, electro dialysis, using the reverse osmosis brackish water desalination method.
\end{abstract}

\section{Introduction}

Water is an important part of all living things, which has both beneficial to the chemical reactions in living organisms, but also conducive to the maintenance of biological temperature stability. At the same time, the human body contains the most amounts of nutrients needed. If the water is lack of the essential elements of human body, or contains some harmful substances, it will be on people's production and life and even life cause's harm. Brackish water is a kind of the high salinity and cannot directly use or the use of poor quality water resources, which is of little value. Its formation is associated with the geographical environment, climatic conditions, geological structure, salt accumulation and pollutant emission factors, and wide distribution, great harmfulness, and brackish water and desalination technology, which has become one of the hot spot the current study.

\section{Overview of brackish water}

The definition of standard. At present, the brackish water has no uniform definition standard. Usually, it is said that the brackish water is for the water salinity in terms of. Hydrological geology the salinity is less than $1000 \mathrm{mg} / \mathrm{L}$ of water into fresh water, more than $1000 \mathrm{~m}$ leave $\mathrm{L}$ water into the brackish water. And the degree of mineralization in the $1000 \wedge-3000 \mathrm{mg} / \mathrm{L}$ water is divided into brackish water, $3000 \wedge-10000 \mathrm{~m}$ leave $\mathrm{L}$ water is divided into saline, $10000^{\wedge}-50000 \mathrm{~m}$ leave $\mathrm{L}$ water division as the brine, greater than $50000 \mathrm{~m}$ leave $\mathrm{L}$ water into brine. Another important indicator of fluoride is also a measure of brackish water, usually also often exceed the standard in the fluoride content in the high salinity water. Both of them tend to be born. Surface water environment quality standard CGB3838- 2002) regulations, surface water source of centralized drinking water fluorine content shall not exceed $1 \mathrm{~m}$ leave $\mathrm{L}$.

The distribution and chemical characteristics of China's salt.Water is different from the northeast to the southwest, which can be divided into 5 type regions in our country according to the chemical characteristics of salt, just as the following figure 1 :

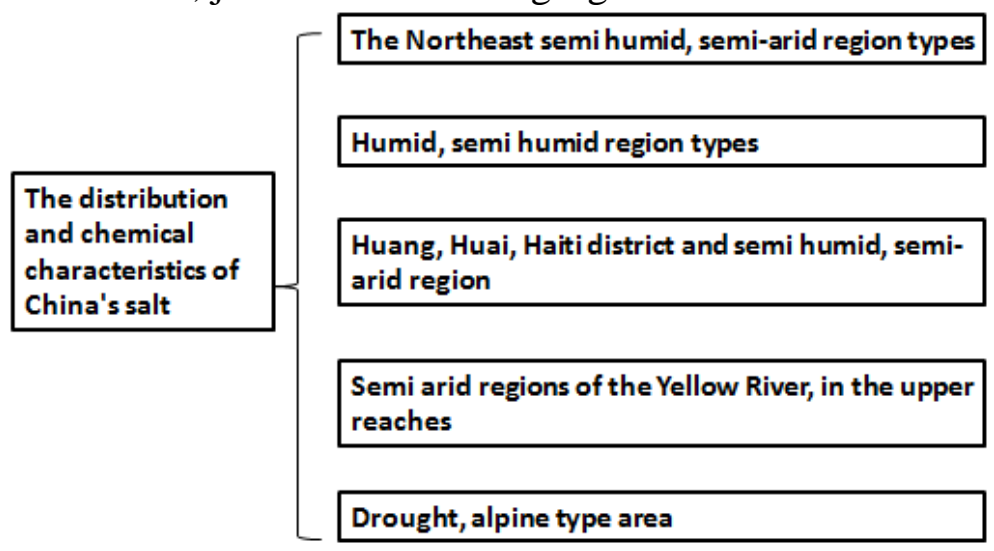

Fig1. The distribution and chemical characteristics of China's salt 
The Northeast semi humid, semi-arid region types. Most of the area of Liaoning, Jilin, Heilongjiang 3 provinces, salt composition of groundwater mainly bicarbonate mainly, also both bicarbonate chloride. It has components of different geographical location of groundwater. Alluvial plain of underground runoff flow, salinity is less, which belongs to the freshwater and salt concentration range. Lacustrine sedimentary plain of groundwater between the low-lying sleepers blisters around the lake.

Humid, semi humid region types. Liaodong Peninsula, Bohai, the Yellow Sea, the East China Sea, South China Sea, the strip belt region, this type of area wide range, large area of saline water, abundant reserves. The main mineral composition of groundwater quality in a sodium chloride dominated, salinity from 1 to $1030 \mathrm{~g} / \mathrm{L}$ o a $2 \mathrm{~g} / \mathrm{L}$

Huang, Huai, Haiti district and semi humid, semi-arid region. In parts of Hebei, Tianjin, Henan, Shandong, Jiangsu, Anhui province have the original type. Different components of different geographic locations of groundwater. The upper part of the plain of alluvial fan in chloride containing sulfuric acid or sulfate chloride based salt concentration. The groundwater is about 3 $\mathrm{Sg} / \mathrm{L}$, which is very close to the coastal zone. The low-lying alluvial deposition plain, groundwater mainly chloride based, salt containing up to 5 about $1 \mathrm{sg} / \mathrm{L}$, some as high as 10-30g/I, ranging from.

Semi arid regions of the Yellow River, in the upper reaches. It is in parts of Shaanxi, Gansu, Qinghai, Ningxia and other provinces, autonomous region. Salt content in groundwater is complex, mainly bicarbonate, chloride, sulfate, carbonate, salt concentration in groundwater ranged from 12 to $2 \mathrm{sg} / \mathrm{L}$ pair, the area of high concentration salt concentration was $10-20 \mathrm{~g} 1 \mathrm{~L}$, the extremely individual area up to more than $30 \mathrm{~g} / \mathrm{L}$.

Drought, alpine type area. Arid region is of Inner Mongolia plateau, arid region of Xinjiang, Inner Mongolia, Qinghai, Xinjiang, Tibet in the extreme arid region, etc.

\section{Causes of brackish water}

Through the analysis of characteristics of environmental isotope, water chemistry simulation and hydrological geological controlling factors analysis, which think that the groundwater in the study area mainly formed by the meteoric water. The surface water is difficult to form a continuous the recharge source of groundwater salt, dissolved a lot of aquifer medium, the salinity increased and the formation of brackish water, just as the following figure 2 :

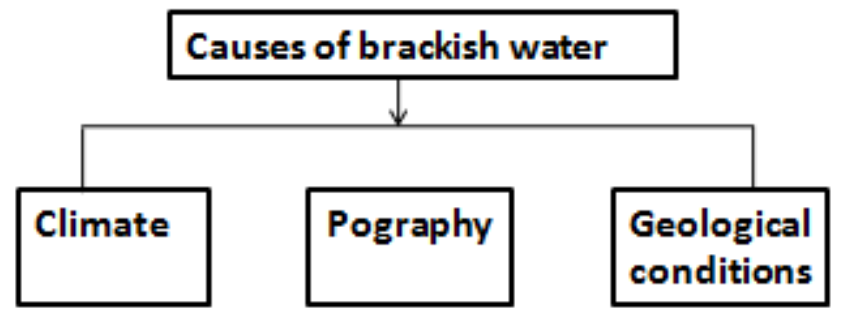

Fig2. Causes of brackish water

Climate. Climate is an important factor affecting the variation of water quality of an area. The most part of Northwest China, arid region of temperate zone, the average annual precipitation is only $200^{\wedge}-300 \mathrm{~mm}$, coupled with high temperatures, evaporation. It increases in dissolution rate of rock salt in water, resulting in increasing salt concentration. It also results in groundwater, surface water for brackish water. On a global scale, as global temperatures rise, evaporation rate continues to accelerate, the concentration of salts in the water increasing, the distribution area of brackish water is increased,

Pography. In the higher areas, due to the long-term leaching, formation salt is low, coupled with the steep slope topography, rock permeability, groundwater runoff way actively, short, fast speed, less salt dissolved in water. The salinity is typically less than $1000 \mathrm{~m} \mathrm{~L}$, and the water quality is better. While the low-lying areas, due to poor permeability of strata, the groundwater flow paths of long, slow, high soluble salt content in formation, the mineralization degree of groundwater is usually greater than $1000 \mathrm{mg} / \mathrm{L}$. The water quality is generally poor, vulnerable to the formation of 
brackish water.

Geological conditions. The changes will affect the local geological conditions of groundwater quality, such as geological structure formed low platform, depression etc. Because of the terrain is closed, the groundwater runoff is stagnant state, the long-term solubility in salt formation. It results that in groundwater mineralization, the degree is high, and the evaporation, intensified by groundwater salt accumulation, the formation of brackish water. In addition, the water blocking faults also can make the original runoff conditions of groundwater and the change in the stagnant condition, the long-term solubility in salt formation and make the water quality variation. At the same time, because the water conducting fracture, the freshwater aquifer with high mineralization saline aquifer butt lead to increase in degree of groundwater mineralization, forming the brackish water.

\section{The development and utilization of brackish water}

Saline water irrigation. The development and utilization of brackish water in the existing America, Israel, Italy and other countries have a long history. The use of technology is also in the continuous improvement. The development and utilization of saline water irrigation and desalination is mainly two aspects. Israel is most typical, desalination technology has entered the industrial production stage, brackish water and saline water total reserves are available for the $58900000000 \mathrm{~m} 3$ to $4000000 \mathrm{~m} 3$, brackish water desalination. The Japanese use of salt concentration for irrigation for 7.0-20g a few tide. India, Spain and other countries with 33g irrigation of wheat, corn, vegetables, water several tobacco and other crops. Tunisia with salt content for cereal crops in groundwater irrigated wheat, maize $4.5 \mathrm{~S} . \mathrm{Sg} 1 \mathrm{~L}$ successfully.

Water desalination. In the past 20 years, much of the rest of the world are rapidly developing desalination to get drinking water reservoir. Today, the world range is from nearly 9000 desalination plant daily production of freshwater $1.6 \times 1 \mathrm{~m} 30$. With the water resource scarcity and demand, it contradictions continue to expand, people committed to the exploitation and utilization of the rich reserves of brackish water resources. Chinese scholars used different methods to desalination of brackish water desalination. After years of research, it obtained great achievements in scientific research, which has opened up a wide door for the exploitation and utilization of brackish water.

Aquaculture. Water quality stabilizing underground salt water has no pollution. Saltwater aquaculture has advantages of small investment, high profits and the cycle is short, quick etc. To obtain the economic benefits of good salt water, the aquaculture uses the Hebei City Yellow disadvantages. Shi Weiliang uses different concentrations of salt water aquaculture shrimp, crab and other major breakthrough. The utilization of salt concentration of $2-3 \mathrm{~g} / \mathrm{L}$ salt water, which is aquaculture with high ornamental Mo dental plaque shrimp, and carry out experimental research on industrialization, and the economic benefits are very good.

\section{Conclusion}

At home and abroad, it has been through the reverse osmosis method, distillation and electro dialysis method to achieve the efficient removal of brackish water, boron, chlorine, fluorine in silicon plasma. But the research mainly focuses on the desalination process and water purification equipment development and discusses the harm. The distribution of brackish water is relatively small, especially the research on the formation mechanism of less aspect. Our country also only causes of northwest of certain provinces of brackish water to do some research. In the study of desalination processing method and process, low efficiency, high operation cost of desalination processing performance is not stable, problems still exist. Therefore, we should explore the causes of brackish water, desalination equipment, which is still the problem of our future research directions. 


\section{Acknowledgment}

Xijing University research, project number: XJ130105.

\section{Reference}

[1] Song Xutong, India Ming Shan. Brackish water desalination solar and desalination by electrodialysis method [M] Beijing: Science Press, 1983

[2] Liu Changming, China's rural drinking water safety Li Mingjuan question and Countermeasure on day. Acta geographica Sinica, 2007, 62: 907-916.

[3] Hu Xinglin, Lan Yongchao, et al. Gansu province brackish water resources amount and its distribution in [CJ\}. Chinese desert, 200.

[4] Li Xiangquan, Yu Qiusheng, Hou Xinwei, et al. Qingshui River basin in Southern Ningxia Bu water circulation characteristics and causes of brackish water day. Hydrogeology and engineering geology, 2006 